\title{
Biocatalytic synthesis of 2-Seleno pyrimidine nucleosides via transglycosylation
}

\author{
Katja F. Hellendahl, ${ }^{1, \#}$ Felix Kaspar, ${ }^{1,2, \#}$ Xinrui Zhou, ${ }^{3}$ Zhaoyi Yang, ${ }^{3}$ Zhen Huang, ${ }^{3}$ Peter Neubauer, ${ }^{1}$ Anke Kurreck ${ }^{1,2 *}$ \\ ${ }^{1}$ Technische Universität Berlin, Chair of Bioprocess Engineering, Straße des 17. Juni 135, D-10623 Berlin, Germany. \\ ${ }^{2}$ BioNukleo GmbH, Ackerstraße 76, D-13355 Berlin, Germany. \\ ${ }^{3}$ Sichuan University, College of Life Sciences, Key Laboratory of Bio-Resource and Eco-Environment of Ministry of \\ Education, No. 17 People's South Road Section 3, 610041, Chengdu, China. \\ \# These authors contributed equally.
}

\begin{abstract}
Selenium-modified nucleosides are powerful tools to study the structure and function of nucleic acids and their protein interactions. The wide-spread application of 2-seleno pyrimidine nucleosides is currently limited by low yields in established synthetic routes. Here, we describe the optimization of the synthesis of 2-Se-uridine and 2-Se-thymidine derivatives by thermostable nucleoside phosphorylases in transglycosylation reactions using natural uridine or thymidine as sugar donors. Reactions were performed at 60 or $80^{\circ} \mathrm{C}$ and at $\mathrm{pH} 9$ under hypoxic conditions to improve the solubility and stability of the 2Se-nucleobases in aqueous media. To optimize the conversion, the reaction equilibria in analytical transglycosylation reactions were studied. The equilibrium constants of phosphorolysis of the 2-Se-pyrimidines were between 5 and 10 and thus belong to the highest described so far. Thus, a ten-fold excess of sugar donor was needed to achieve $40-48 \%$ conversion to the target nucleoside. Scale-up of the optimized conditions provided four Se-containing nucleosides in 6-40\% isolated yield which compares favorably to established chemical routes.
\end{abstract}

Selenium derivatization is a powerful tool for structure and function studies of nucleic acids. The distinct steric and electronic properties of selenium have facilitated the X-ray structural analysis of DNA and RNA as well as their interactions with proteins. ${ }^{[1-3]}$ Notably, this technique has been applied for the investigation of ribozymes, ${ }^{[4]}$ riboswitches, ${ }^{[5]}$ homo-DNA, ${ }^{[6]}$ and for HIV-1 drug discovery. ${ }^{[7]}$ Besides their application in X-ray crystallography, selenium-modified nucleic acids are potential therapeutics for the treatment of cancer, ${ }^{[8,9]}$ as well as vira ${ }^{[10-12]}$ or bacterial infections. ${ }^{[13]}$ In addition, they have attracted interest as diagnostic agents. ${ }^{[14]}$ Several types of selenium derivatization of nucleic acids have been described which include replacement of an oxygen atom by selenium either in the nucleobase, the sugar moiety or in the phosphate groups of a nucleoside or nucleotide (please see ${ }^{[1-3]}$ for reviews).

Despite their demand in chemical biology, a high-yielding and sustainable synthesis of Se-containing nucleosides has not yet been described. Previous work has established that 2-Se pyrimidine nucleosides can be accessed either from methylated sulfo-nucleosides or via selenation of isocytidine (Scheme 1). ${ }^{[15-21]}$ However, these chemical syntheses have several drawbacks, including the need for multi-step routes starting from a natural nucleoside, as well as an unfavorable atom economy and the extensive use of organic solvents.

In a proof-of-concept study, we recently described a protecting group-free biocatalytic route for the synthesis of Se-containing pyrimidine nucleosides (Scheme 1). ${ }^{[22]} \mathrm{We}$ demonstrated on an analytical scale that 2- and 4-Sesubstituted pyrimidine nucleosides can be prepared via transglycosylation reactions catalyzed by thermostable nucleoside phosphorylases (NPs).

NPs perform the reversible phosphorolysis of nucleosides to pentose-1-phosphates and nucleobases. By coupling the enzymatic phosphorolysis of a sugar donor with the glycosylation of a free nucleobase in situ, nucleosides can formally be synthesized directly from their corresponding nucleobases. The application of these enzymes resolves the need for protecting groups, laborious preparation as well as isolation of sugar synthons, ${ }^{[23]}$ and furthermore greatly reduces the use of toxic organic solvents by employing aqueous systems $^{[24,25]}$ (for reviews, see ${ }^{[26,27]}$ ).

Nevertheless, several challenges remained to be addressed for the biocatalytic synthesis of Se-containing nucleosides using NPs. These include the poor solubility of the free Se-nucleobases in water, which has so far restricted substrate loading to approximately $1 \mathrm{mM}$. Furthermore, low substrate conversion was observed, ${ }^{[22]}$ indicating that the reaction equilibria of these reactions might be unfavorable. Additionally, prolonged reaction times have been shown to cause unwanted side reactions such as oxidation and deselenation of the starting material, ${ }^{[22,28-30]}$ resulting in heavy losses of the targeted product.

In this work, we addressed these obstacles by adjusting the reaction conditions to accommodate for the solubility and stability of Se-nucleobases in the biocatalytic synthesis of 2-Se-pyrimidine nucleosides. Working under hypoxic conditions prevented deselenation and oxidative loss of yield while an increased reaction $\mathrm{pH}$ allowed for higher substrate loading enabled by deprotonation of the Senucleobases. A thermodynamic characterization of the reaction equilibria via analytical transglycosylations revealed equilibrium constants well outside the known range of similar nucleosides and guided our choice of suitable reaction conditions to maximize the product yields. This report presents improved yields compared to established procedures and describes the first biocatalytic synthesis of 2-Se-pyrimidine nucleosides.

\section{Results and Discussion \\ Optimization of the reaction conditions to improve substrate loading of the 2-Se-bases}

We aimed to access the selenium-modified nucleosides $\mathbf{1 a}-\mathbf{2 b}$ in a biocatalytic one-pot approach using thermostable NPs (Scheme 2). For this study we selected the commercially available pyrimidine nucleoside phosphorylase PyNP-04 ${ }^{[31]}$ due to its thermostability and broad substrate spectrum. Analytical-scale experiments in our previous report ${ }^{[22]}$ indicated that these compounds can, in principle, be synthesized via transglycosylation starting 


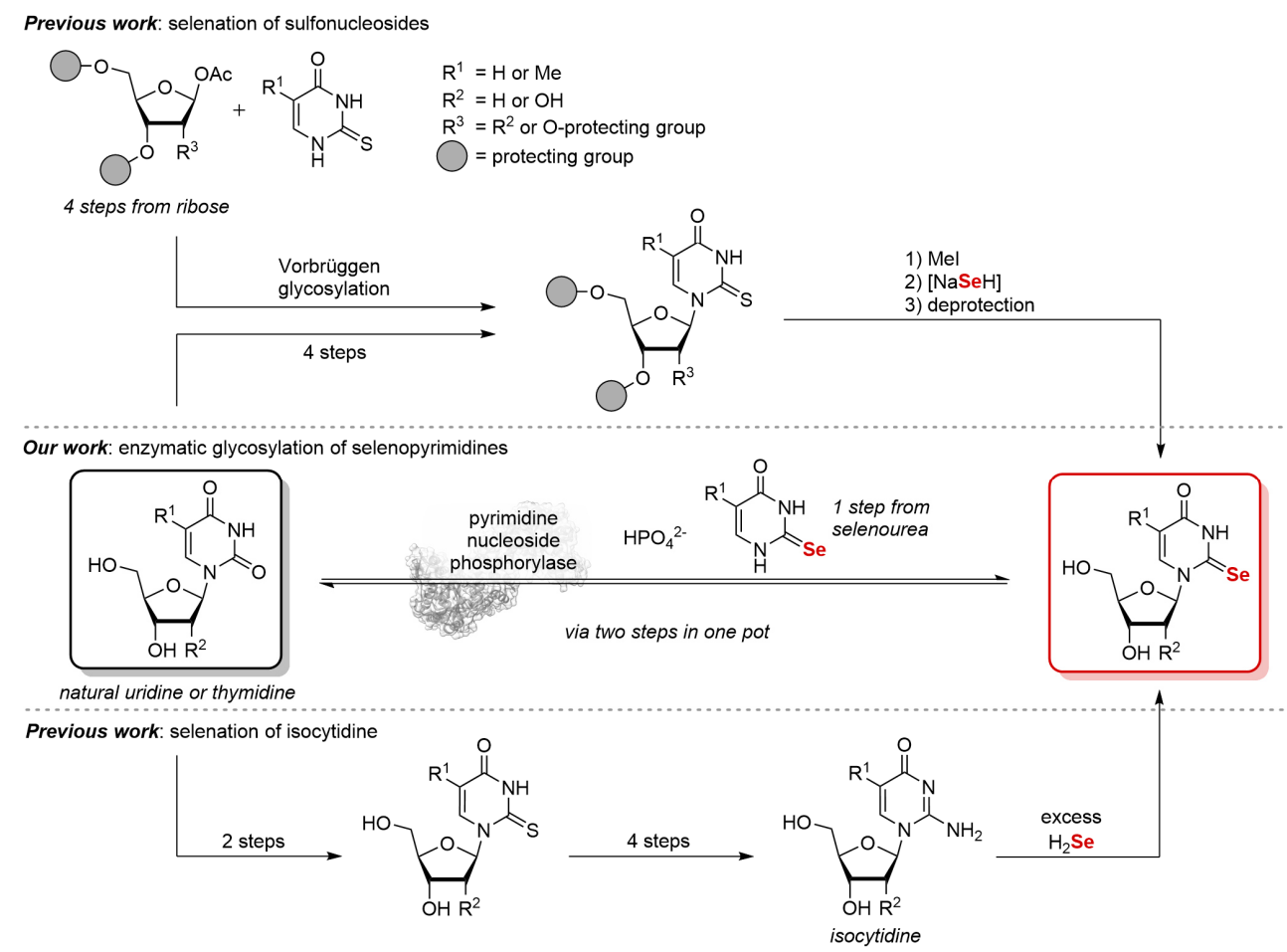

Scheme 1. Approaches to the synthesis of 2-Se pyrimidine nucleosides. Previous work has established introduction of selenium via a methylated sulfo-nucleoside or selenation of isocytidine. Our work aims for biocatalytic direct glycosylation of a selenium-containing nucleobase.

from the natural nucleosides uridine or thymidine and a selenium-containing nucleobase.

For synthetic applications, a higher substrate loading than previously employed (1 $\mathrm{mM}$ at $\mathrm{pH} 7)$ would be highly desirable to reduce solvent use and facilitate purification. Based on the $\mathrm{pK}_{\mathrm{a}}$ of 2 -Se-uracil (1) $(7.18 \text { at } \mathrm{RT})^{[32]}$ we hypothesized that a slightly higher reaction $\mathrm{pH}$ would facilitate dissolution of $\mathbf{1}$ and 2-Se-thymine (2) as their corresponding anions. Since it was not available from the literature, we determined the $\mathrm{pK}_{\mathrm{a}}$ of $\mathbf{2}$ through analysis of its $\mathrm{UV}$ absorption spectra at different $\mathrm{pH}$ values and found a similar value $(7.49 \pm 0.01$, Figure $\mathrm{S} 1)$ to that of $\mathbf{1}$. Hence, compared to the natural nucleobases, the Se-containing analogues were more acidic. ${ }^{[16,32]} \mathrm{Next}$, we investigated the solubility of $\mathbf{1}$ and $\mathbf{2}$ at $\mathrm{pH}$ values below and above their $\mathrm{pK}_{\mathrm{a}}$ to see if a pH shift would allow higher substrate loading. At $\mathrm{pH} 7,1$ was not soluble at $10 \mathrm{mM}$, as indicated by the presence of precipitate (Figure S2). In contrast, full dissolution was observed at $\mathrm{pH} 9$, confirming that a higher reaction $\mathrm{pH}$ can increase the solubility of the free nucleobase through deprotonation and solvation of the corresponding salt. Nonetheless, this effect was modest, as only 2 was fully soluble at $20 \mathrm{mM}$ at pH 9 and RT.

A reaction temperature of $80^{\circ} \mathrm{C}$ was initially chosen for the synthesis of Se-modified nucleosides as higher reaction rates are observed with the enzyme and it can be assumed that a high reaction temperature would further improve the solubility of $\mathbf{1}$ and $\mathbf{2}$. Initial studies, however, revealed product losses during the synthesis of 2'-deoxyribonucleosides (data not shown) which can be correlated to the hydrolysis of the transglycosylation intermediate $\mathbf{b}^{\text {' at }}$ higher temperatures. ${ }^{[24,33]}$ Hence, reaction temperatures of $80{ }^{\circ} \mathrm{C}$ were applied for the synthesis of ribonucleosides, while $60^{\circ} \mathrm{C}$ was chosen for reactions involving 2'deoxynucleosides.

As the $\mathrm{pH}$ and temperature might influence the activity of PyNP-04, we determined specific activities of the enzyme at $\mathrm{pH} 7$ or 9 . To this end, we performed phosphorolysis reactions (Figure $\mathrm{S} 3 \mathrm{~A}$ ) with the sugar donors uridine (a) and thymidine (b) in a MOPS ( $\mathrm{pH} 7)$ or glycine buffer ( $\mathrm{pH} 9)$. PyNP-04 was active under all conditions and, for instance, catalyzed the phosphorolysis of a at $80{ }^{\circ} \mathrm{C}$ with activities of approximately $80 \mathrm{U} \mathrm{mg}^{-1}$ (Figure S3B). We additionally
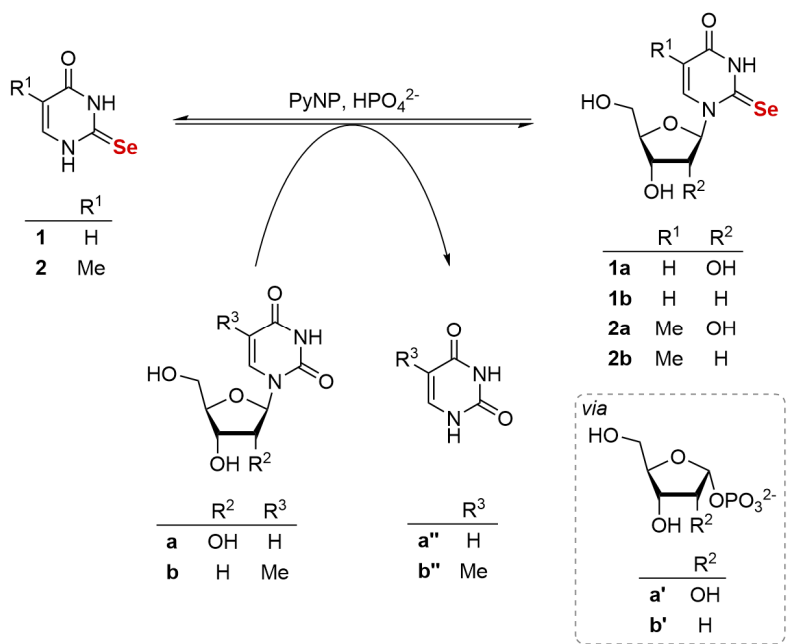

Scheme 2. Biocatalytic synthesis of 2-Seleno pyrimidine nucleosides via transglycosylation reactions using a thermostable pyrimidine nucleoside phosphorylase (PyNP) as biocatalyst. 
performed the glycosylation of $\mathbf{2}$ with the sugar phosphate a' to confirm that the higher reaction $\mathrm{pH}$ did not inhibit the second reaction step (reverse phosphorolysis). We observed no significant difference in glycosylation activity at $\mathrm{pH} 7$ or 9 , indicating that the deprotonated Se-base is well-accepted by the enzyme (Figure S4). Taken together, these data show that a reaction $\mathrm{pH}$ of 9 improves the solubility of $\mathbf{1}$ and $\mathbf{2}$ and thus permits higher substrate loadings, while still allowing excellent enzymatic activity, with reaction temperatures of $60^{\circ} \mathrm{C}$ or $80^{\circ} \mathrm{C}$ presumably facilitating additional solubility.

\section{Hypoxic conditions for the stability of the 2-Se-bases}

The application of an alkaline reaction environment and high temperatures guided us to explore the stability of the 2Se-bases under these rather harsh conditions. In early experiments we noticed significant oxidation of the starting materials $\mathbf{1}$ and $\mathbf{2}$ which manifested itself as a loss of substrate and product, as observed by HPLC, as well as discoloration of the reaction mixtures from colorless to red and black (data not shown). To prevent oxidation and deselenation, reducing agents, ${ }^{[28-30]}$ such as dithiothreitol (DTT) and ascorbic acid, and inert gases ${ }^{[17]}$ like argon and nitrogen have previously been applied in chemical syntheses and redox studies. This led us to examine whether and for how long the stability of the 2-Se-bases can be increased by the application of DTT and/or a nitrogen atmosphere, which appeared compatible with our reaction system. To this end, we incubated $\mathbf{1}$ and $\mathbf{2}$ in different buffer systems (glycine/ $\mathrm{NaOH} \mathrm{pH}$, with or without DTT and with or without a nitrogen atmosphere) at $80^{\circ} \mathrm{C}$ and analyzed samples at different time points to check for the integrity of the starting material. Without any additives, oxidation products were already detected after $2 \mathrm{~h}$, with most of the Se-base being degraded after $24 \mathrm{~h}$ (Figure 1A and S4). The addition of DTT had a slightly conserving effect, since no oxidation was apparent after $2 \mathrm{~h}$, but significant deselenation was apparent after 4 and $24 \mathrm{~h}$ (Figure 1B and S5). In contrast, saturation of the solution with nitrogen almost completely prevented oxidation of $\mathbf{1}$ and $\mathbf{2}$, with only minimal oxidation product being detectable after $24 \mathrm{~h}$ (Figure 1C and S5). As expected, combining DTT and nitrogen prevented oxidation completely and conserved the starting material for $24 \mathrm{~h}$ (Figure 1D and S5).

Having established that DTT and nitrogen aid in stabilization of $\mathbf{1}$ and $\mathbf{2}$, we questioned if these conditions would affect the activity of PyNP-04. Therefore, we performed phosphorolysis experiments at $80{ }^{\circ} \mathrm{C}$ with either a in nitrogen-saturated buffer or the model substrate 5iodouridine (c) in buffer with $5 \mathrm{mM} \mathrm{DTT}$, as the latter nucleoside allowed us to obtain UV spectra that could be deconvoluted despite the heavy background absorption of DTT at lower wavelengths (see Figure S3 of ref. ${ }^{[34]}$ ). In contrast to the comparable activity observed in nitrogensaturated buffer, the application of DTT caused a $\approx 40 \%$ drop in enzymatic activity with our model substrate c (160 $\mathrm{U} \mathrm{mg}^{-1}$ to $95 \mathrm{U} \mathrm{mg}^{-1}$; Figure S3B). However, due to the prevention of oxidation by DTT, we considered this decrease in enzymatic activity tolerable and proceeded with these conditions. In summary, the application of hypoxic conditions combined with the reducing agent DTT improved the stability of $\mathbf{1}$ and $\mathbf{2}$ in aqueous solution with
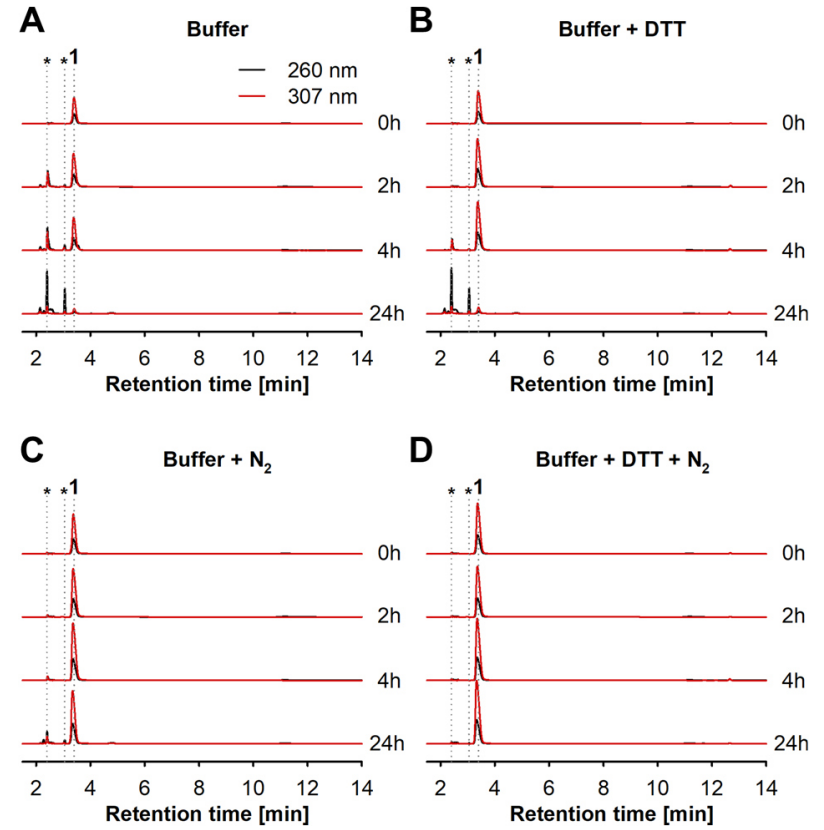

Figure 1. Stability of $5 \mathrm{mM} 1$ at $80^{\circ} \mathrm{C}$ in $50 \mathrm{mM}$ glycine/ $\mathrm{NaOH}$ buffer $\mathrm{pH} 9$ without additives (A), with $5 \mathrm{mM}$ DTT (B), saturated with nitrogen (C) and the combination of $5 \mathrm{mM}$ DTT and nitrogen (D). Samples were analyzed at $260 \mathrm{~nm}$ (black) and $307 \mathrm{~nm}$ (red). The typical retention time of $\mathbf{1}$ is $3.4 \mathrm{~min}$ and the degradation products appear at $2.4 \mathrm{~min}$ and $3 \mathrm{~min}$. Similar results were obtained for 2 (Figure S5). Please see the externally hosted Supporting Information for raw data. ${ }^{[3]}$

no detectable degradation after $24 \mathrm{~h}$ at $80^{\circ} \mathrm{C}$, while only slightly affecting the enzymatic activity.

Optimization of the enzymatic synthesis of 2-Sepyrimidine nucleosides based on thermodynamic calculations

With hypoxic and alkaline reaction conditions in hand which served well to ensure solubility and stability of the nucleobases $\mathbf{1}$ and $\mathbf{2}$, we turned our attention to the improvement of the previously observed low conversions. ${ }^{[22]}$ Recent work from our group had demonstrated the application of analytical-scale experiments and thermodynamic calculations for the yield optimization in NP-catalyzed transglycosylations. ${ }^{[36]}$ Therefore, we sought to transfer the same principles which had succeed for the synthesis of dihalogenated nucleosides $^{[36,37]}$ to the preparation of Se-pyrimidines to obtain improved yields. Since nucleoside phosphorolysis (and consequently also the reverse reaction, glycosylation) is a thermodynamically controlled reaction, one may calculate the equilibrium state of transglycosylations via the corresponding equilibrium constants. Thus, when both equilibrium constants in the system are known, conversions can be optimized in silico to suggest conditions that enable the desired extent of product formation (for further details, please see ${ }^{[37]}$ ).

Equilibrium constants for the phosphorolysis of the sugar donors have been described recently for a broad temperature range, ${ }^{[38]}$ but the corresponding values for 2 -Se-nucleosides have not been reported yet. Since these constants are 
A

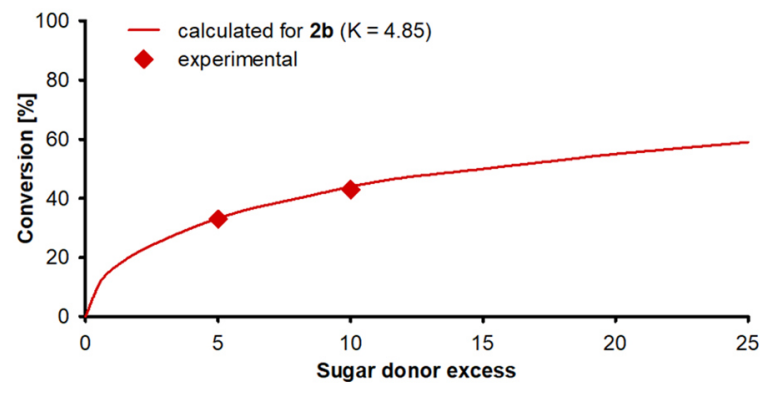

B

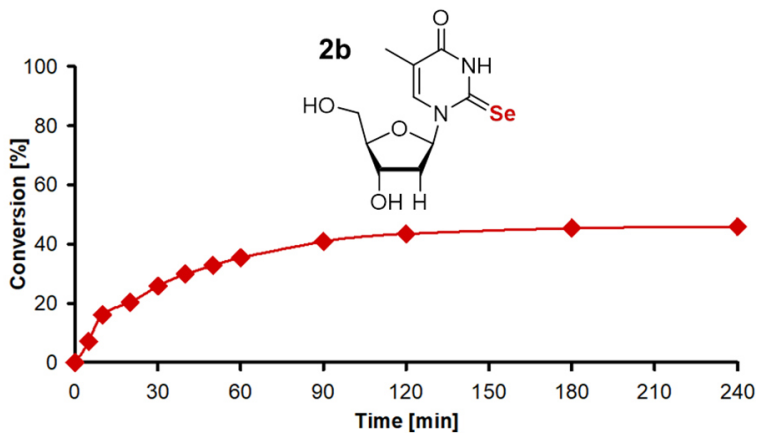

Figure 2. Optimization of the enzymatic synthesis of $\mathbf{2 b}$. Transglycosylation reactions were performed in a total volume of $1 \mathrm{~mL}$ using $1 \mathrm{mM}$ (A) or $5 \mathrm{mM}$ (B) 2 and $5 \mathrm{mM}$ DTT in $50 \mathrm{mM}$ glycine/ $\mathrm{NaOH}$ buffer $\mathrm{pH} 9$ at $60{ }^{\circ} \mathrm{C}$ with either 5 -fold (A) or 10 -fold (A, B) excess of $\mathbf{b}$ compared to the nucleobase 2. Final concentrations of PyNP-04 of $50.4 \mu \mathrm{g} \mathrm{mL} \mathrm{m}^{-1}$ (around $4 \mathrm{U}$, A) and $24.6 \mu \mathrm{g} \mathrm{mL}^{-1}$ (around $2 \mathrm{U}, \mathrm{B}$ ) were applied. Experimental conversion was determined by HPLC as the conversion of 2 to 2b. The equilibrium constant of phosphorolysis was calculated based on the experimental data of the 5-fold sugar donor excess (A). Predictions of the conversion using different sugar donor to nucleobase ratios were carried out as described previously. ${ }^{[37]}$ Similar results were obtained for the other products (Table 1). Please see the externally hosted Supporting Information for raw data and calculations. ${ }^{[34]}$

Table 1. Equilibrium state thermodynamic calculations were used to determine appropriate reaction conditions for the synthesis of $\mathbf{1 a}-\mathbf{2 b}$

\begin{tabular}{|c|c|c|c|c|c|}
\hline \multirow{2}{*}{ Product } & \multirow{2}{*}{$\begin{array}{l}\text { Product formation }[\%] \text { at } \\
\text { equilibrium for } 5 \text {-fold } \\
\text { sugar donor excess }\end{array}$} & \multirow{2}{*}{$\begin{array}{l}\text { Equilibrium } \\
\text { constant of } \\
\text { phosphorolysis }\end{array}$} & \multicolumn{3}{|c|}{$\begin{array}{l}\text { Product formation [\%] at equilibrium for } 10 \text {-fold sugar donor } \\
\text { excess }\end{array}$} \\
\hline & & & calculated $^{[\mathrm{a}]}$ & $\begin{array}{c}\text { experimental } \\
(1 \mathrm{mM} \text { nucleobase })^{[\mathrm{b}]}\end{array}$ & $\begin{array}{c}\text { experimental } \\
(5 \mathrm{mM} \text { nucleobase })^{[\mathrm{c}]}\end{array}$ \\
\hline $1 \mathbf{a}$ & 30.5 & 9.37 & 39 & 40 & $46(4 \mathrm{~h})$ \\
\hline $1 b$ & 30 & 6.07 & 40 & 40 & $39(3 \mathrm{~h})$ \\
\hline $2 \mathbf{a}$ & 35 & 6.75 & 44 & 47 & $48(4 \mathrm{~h})$ \\
\hline $2 \mathbf{b}$ & 33 & 4.85 & 44 & 43 & $45(3 \mathrm{~h})$ \\
\hline
\end{tabular}

Transglycosylation reactions were performed in a total volume of $1 \mathrm{~mL}$ in $50 \mathrm{mM}$ glycine/NaOH buffer $\mathrm{pH} 9$ and $5 \mathrm{mM}$

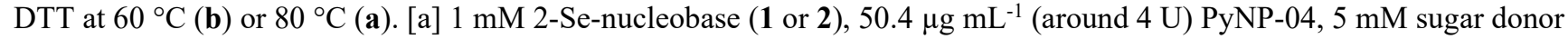
(a or b). [b] $1 \mathrm{mM}$ 2-Se-nucleobase (1 or 2), $50.4 \mu \mathrm{g} \mathrm{mL}-1$ (around $4 \mathrm{U}$ ) PyNP-04, $10 \mathrm{mM}$ sugar donor (a or b). [c] $5 \mathrm{mM}$ 2-Se-nucleobase (1 or 2), $24.6 \mu \mathrm{g} \mathrm{mL}^{-1}$ (around $2 \mathrm{U}$ ) PyNP-04, $50 \mathrm{mM}$ sugar donor (a or b).

Experimental conversion was determined by HPLC. Equilibrium constants were calculated with the experimental data of the 5-fold sugar donor excess. Predictions of the conversion using 10-fold sugar donor excess were carried out as described previously. ${ }^{[37]}$ Please see the externally hosted Supporting Information for raw data and calculations. ${ }^{[34]}$

required for yield optimization via equilibrium thermodynamics, we performed small-scale transglycosylation reactions to determine these indirectly. Using a five-fold excess of the sugar donor over the Senucleobase and 0.09 equivalents of phosphate, equilibrium conversions between 30 and $35 \%$ were observed (Table 1 , Figure $2 \mathrm{~A}$ for $\mathbf{2 b}$ as a visual example). This yielded equilibrium constants of the phosphorolysis of the Senucleosides $\mathbf{1 a}-\mathbf{2 b}$ in the range of 5 to 10 (Table 1). Interestingly, these equilibrium constants surpass those of other natural and modified pyrimidine nucleosides $(0.1-0.8)^{[37-39]}$ by around an order of magnitude. While the reason for these high equilibrium constants is unclear to date, we hypothesize that the increased electron density near the glycosylation site may contribute to a weaker C1'-N1 bond.

Next, we used thermodynamic calculations to predict the maximum conversions in transglycosylation reactions employing different sugar donor excesses (Figure 2A, Table 1). These predictions revealed that the high equilibrium constants of phosphorolysis of the target nucleosides limited the maximum conversion severely. For example, to obtain $50 \%$ conversion to the Se-nucleoside 1a, an approximately 20 -fold excess of the sugar donor a would be necessary. However, such a high sugar donor excess is not suitable for preparative experiments due to high substrate costs and waste. In addition, we expected that this would also prevent an efficient workup and purification. Thus, we applied a sugar donor excess of 10 as a compromise to the aforementioned issues and maximum conversion. Although other sugar donors such as 5ethynyluridine or 7-methylguanosine or direct glycosylation approaches with the sugar phosphates a' or b' might provide higher conversions than the application of natural uridine (a) and thymidine (b), these starting materials are considerably more expensive and would render this synthetic approach unfeasible (Table S1). Therefore, we decided to employ cheaply available $\mathbf{a}$ and $\mathbf{b}$ as sugar donors, which conveniently also offer some of the more favorable equilibrium constants of phosphorolysis among the natural nucleosides. ${ }^{[38]}$

Finally, we confirmed our predictions for 10 equivalents of $\mathbf{a}$ or $\mathbf{b}$ and evaluated the reaction times until equilibrium in analytical-scale experiments under optimized conditions. 
The predicted extent of product formation was observed for all four 2-Se-nucleosides (Figure 2B, Table 1) with reaction completion occurring within 3 to $4 \mathrm{~h}$. Taken together, our thermodynamic characterization of the reaction system revealed unfavorable equilibrium constants of phosphorolysis of all Se-containing target nucleosides, severely limiting the maximum conversion achievable in transglycosylation reactions. However, a 10-fold excess of the sugar donors allowed for $40-48 \%$ conversion for all Senucleosides.

\section{Enzymatic synthesis and purification in semi- preparative scale}

After optimizing the synthesis under hypoxic and alkaline reaction conditions in small-scale experiments, we aimed to synthesize and purify the four 2-Seleno pyrimidines in semipreparative scale. Therefore, the optimized reaction conditions were up-scaled to a volume of $50 \mathrm{~mL}$ with $5 \mathrm{mM}$ 2-Se-nucleobase. The observed product formations in the larger scale of $41-47 \%$ after $3(\mathbf{2 b}), 4(\mathbf{1 b})$ or $5 \mathrm{~h}(\mathbf{1 a}, \mathbf{2 a})$ (Table 2) were in good accordance with the small-scale experiments. Purification of the target compounds from these reaction mixtures, however, proved rather challenging due to the presence of large quantities of unreacted sugar donor. In fact, our attempts to purify any of the products by preparative HPLC were unsuccessful as the obtained material persistently contained sugar donor starting material. Therefore, we applied an initial silica chromatography step on normal phase to remove most of the sugar donor, followed by a second purification step via preparative HPLC. Using this two-step process, we obtained 4.9-29.5 $\mathrm{mg}$ of the target nucleosides, corresponding to isolated yields of 6-40\% (Table 2, Figure S6-S9). Despite the incomplete conversions and product losses during purification, our biocatalytic route compares favorably to its chemical counterparts where yields of less than $10 \%$ are typically achieved. ${ }^{[22]}$

Table 2. Yields and purity of 2-Se-pyrimidine nucleosides

\begin{tabular}{cccc} 
Product & $\begin{array}{c}\text { Conversion } \\
{[\%]} \\
\text { (Time }[\mathrm{h}])\end{array}$ & $\begin{array}{c}\text { Isolated } \\
\text { yield }[\mathrm{mg}] \\
([\%])\end{array}$ & $\begin{array}{c}\text { Purity } \\
{[\%]^{[\mathrm{a}]}}\end{array}$ \\
\hline 1a & $44(5)$ & $4.9(6.3)$ & 98 \\
$1 \mathrm{~b}$ & $41(4)$ & $29.5(40.5)$ & 94 \\
$2 \mathrm{a}$ & $47(5)$ & $20.8(25.9)$ & 99 \\
$2 \mathrm{~b}$ & $45(3)$ & $9.6(12.5)$ & 99 \\
\hline
\end{tabular}

The $50 \mathrm{~mL}$ reaction mixture consisted of $5 \mathrm{mM}$ 2-Se-base (1 or 2), $50 \mathrm{mM}$ sugar donor (a or b), $5 \mathrm{mM}$ DTT and $24.6 \mu \mathrm{g} \mathrm{mL}^{-1}$ (around 98 U) PyNP-04 in $50 \mathrm{mM}$ glycine/ $\mathrm{NaOH}$ buffer $\mathrm{pH} 9$ saturated with nitrogen. The reaction temperature was $60^{\circ} \mathrm{C}(\mathbf{1 b}, \mathbf{2 b})$ or $80^{\circ} \mathrm{C}(\mathbf{1 a}$, 2a). [a] Purity was determined via analytical HPLC. Please see the externally hosted Supporting Information for raw data.

\section{Conclusion}

This work presents a biocatalytic synthesis of 2-Sepyrimidine nucleosides via transglycosylation from uridine or thymidine. Following a thermodynamic characterization of the phosphorolysis of the target nucleosides on a small scale, four selenium-containing pyrimidine nucleosides were obtained in scale-up experiments where alkaline and hypoxic conditions, as well as high temperatures, enabled sufficient solubility and stability of the starting materials. Although the present route delivers improved yields compared to previous efforts, product purification currently represents a major bottleneck and needs to be addressed in future studies.

\section{Experimental Section \\ General Information}

All chemicals and solvents were of analytical grade or higher and purchased, if not stated otherwise, from SigmaAldrich (Steinheim, Germany), Carl Roth (Karlsruhe, Germany), TCI Deutschland (Eschborn, Germany), Carbosynth (Berkshire, UK) or VWR (Darmstadt, Germany). 2-Se-uracil (1) and 2-Se-thymine (2) were prepared according to literature procedures. ${ }^{[32]}$

The thermostable nucleoside phosphorylase PyNP-04 (EPyNP-0004) $)^{[31]}$ was obtained from BioNukleo $\mathrm{GmbH}$ (Berlin, Germany) and used as recommended by the manufacturer. PyNP-04 was heterologously expressed in Escherichia coli and purified by affinity chromatography. The provided stock solution $\left(1.12 \mathrm{mg} \mathrm{mL}^{-1}\right)$ was stored at $4{ }^{\circ} \mathrm{C}$. The enzyme originates from a thermophilic bacterium with an optimum growth temperature of $80^{\circ} \mathrm{C}$.

All UV/Vis absorption spectra were recorded with a BioTek PowerWave HT plate reader using UV/VIStransparent 96-well plates (UV-STAR F-Bottom \#655801, Greiner Bio-One). All raw and calculated data described in this article are freely available from an external online repository. ${ }^{[34]}$

\section{Determination of the dissociation constant $\left(\mathrm{pK}_{\mathrm{a}}\right)$ of 2-Se- modified nucleobases}

The $\mathrm{pK}_{\mathrm{a}}$ of $\mathbf{1}$ and $\mathbf{2}$ was determined by analysis of their $\mathrm{UV} / \mathrm{V}$ is absorption spectra between $\mathrm{pH} 4$ and $\mathrm{pH} 10$ at RT. In a total volume of $10 \mathrm{~mL}$, the nucleobases were dissolved to a concentration of $100 \mu \mathrm{M}$ in $50 \mathrm{mM}$ MOPS buffer (initially $\mathrm{pH} 9$ ). Desired $\mathrm{pH}$ values were adjusted with $\mathrm{HCl}$ and $\mathrm{NaOH}$ and samples of $200 \mu \mathrm{L}$ were transferred to a UV/Vis-transparent 96-well plate to record the UV absorption spectra in the range of 250 to $350 \mathrm{~nm}$ in steps of $1 \mathrm{~nm}$. The spectra were analyzed via spectral unmixing as previously described ${ }^{[35,40]}$ using a fully protonated $(\mathrm{pH} 4)$ and a fully deprotonated $(\mathrm{pH} \mathrm{10)}$ spectrum as substrate and product reference for the deprotonation reaction, as spectra obtained near these $\mathrm{pH}$ values displayed identical shape (indicating no further reaction). For the determination of the $\mathrm{pK}_{\mathrm{a}}$, the experimental data were fitted to equation (1), whereby the $\mathrm{pH}$ was set as the input variable, $\alpha$ as the dependent variable and $\mathrm{pK}_{\mathrm{a}}$ as the parameter to fit. ${ }^{[41]}$

$$
a=\frac{x_{\text {deprot }}}{x_{\text {deprot }}+x_{\text {prot }}}=\frac{10^{p H-p K_{a}}}{1+10^{p H-p K_{a}}}
$$




\section{Solubility of the 2-Se-modified nucleobases}

The solubility of $\mathbf{1}$ and $\mathbf{2}$ was tested in $50 \mathrm{mM}$ MOPS/NaOH buffer $\mathrm{pH} 7$ and $50 \mathrm{mM}$ glycine/ $\mathrm{NaOH}$ buffer $\mathrm{pH} 9$ at RT. In a total volume of 0.3 to $10 \mathrm{~mL}$, the nucleobases were dissolved to concentrations of $1 \mathrm{mM}, 5 \mathrm{mM}, 10 \mathrm{mM}$ and $20 \mathrm{mM}$. The solutions were observed for the occurrence of precipitate.

\section{Stability of the 2-Se-modified nucleobases}

The stability of $\mathbf{1}$ and 2 was analyzed at $80{ }^{\circ} \mathrm{C}$ in Pyrex ${ }^{\circledR}$ glass tubes with screw caps. Therefore, the nucleobases were dissolved to a concentration of $5 \mathrm{mM}$ in the following four buffers: (a) $50 \mathrm{mM}$ glycine/ $\mathrm{NaOH}$ buffer $\mathrm{pH} 9$, (b) $50 \mathrm{mM}$ glycine/NaOH buffer pH 9 with $5 \mathrm{mM}$ 1,4dithioreitol (DTT), (c) $50 \mathrm{mM}$ glycine/ $\mathrm{NaOH}$ buffer $\mathrm{pH} 9$, saturated with nitrogen and (d) $50 \mathrm{mM}$ gylcine $/ \mathrm{NaOH}$ buffer $\mathrm{pH} 9$ with $5 \mathrm{mM}$ DTT, saturated with nitrogen. Samples were taken after $0 \mathrm{~h}, 2 \mathrm{~h}, 4 \mathrm{~h}$ and $24 \mathrm{~h}$, and diluted to a final concentration of $1 \mathrm{mM}$ nucleobase with $\mathrm{MeOH}$. After centrifugation $\left(4{ }^{\circ} \mathrm{C}\right.$ and $21,500 \mathrm{~g}$ for $20 \mathrm{~min}$ ), samples were analyzed by analytical HPLC as described below.

\section{Enzyme activity assays}

The activity of PyNP-04 was determined by performing phosphorolysis reactions with the substrates uridine (a), thymidine (b) and the model substrate 5-iodouridine (c). Samples were analyzed by the UV/Vis spectroscopy-based assay described recently. ${ }^{[35,40]}$ Briefly, a $500 \mu \mathrm{L}$ reaction mixture consisting of $1 \mathrm{mM}$ nucleoside and $50 \mathrm{mM} \mathrm{K}_{2} \mathrm{HPO}_{4}$ in $50 \mathrm{mM}$ buffer (glycine/ $\mathrm{NaOH} \mathrm{pH} 9$ or $\mathrm{MOPS} / \mathrm{NaOH}$ $\mathrm{pH} 7)$ was preheated to the desired temperature $\left(60{ }^{\circ} \mathrm{C}\right.$ or $\left.80^{\circ} \mathrm{C}\right)$. The reaction was started by the addition of the enzyme (typically $10 \mu \mathrm{L}$ of enzyme stock solution prediluted in $2 \mathrm{mM}$ potassium phosphate buffer $\mathrm{pH} 7$ ). Final concentrations of PyNP-04 from 150 to $750 \mathrm{ng} \mathrm{mL}^{-1}$ were applied. At timely intervals, samples of $60 \mu \mathrm{L}$ were taken and quenched in $450 \mu \mathrm{L} 100 \mathrm{mM} \mathrm{NaOH}$ and $200 \mu \mathrm{L}$ of the diluted sample was transferred to a UV/Vis-transparent 96well plate to record the UV absorption spectra from 250 to $350 \mathrm{~nm}$ in steps of $1 \mathrm{~nm}$. Spectral analysis was carried out as described previously ${ }^{[35,40]}$ with software ${ }^{[42]}$ and reference spectra $^{[43]}$ freely available online.

To assay PyNP-04 for the glycosylation of the Senucleobase 2, reactions consisting of $1 \mathrm{mM} \mathrm{2,10} \mathrm{mM} \mathbf{b}$ ' and $70 \mu \mathrm{g} \mathrm{mL}^{-1}$ enzyme in $50 \mathrm{mM}$ glycine/ $\mathrm{NaOH}$ buffer $\mathrm{pH} 9$ were monitored. For analysis, samples of $60 \mu \mathrm{L}$ were withdrawn, quenched in an equal volume of $\mathrm{MeOH}$ and diluted with $400 \mu \mathrm{L} 100 \mathrm{mM}$ glycine/NaOH buffer $\mathrm{pH} 10$. The experimental spectra were fitted with corresponding reference spectra of $\mathbf{2}$ and $\mathbf{2 b}$ obtained under the same conditions.

One unit (U) of enzyme activity was defined as the amount of the enzyme catalyzing the conversion of $1 \mu \mathrm{mol}$ of substrate per minute under the described assay conditions.

\section{Optimization of the enzymatic synthesis of 2-Se- modified nucleosides}

The 2-Se-modified nucleosides $\mathbf{1} \mathbf{a}-\mathbf{2} \mathbf{b}$ were accessed in a one-pot transglycosylation reaction using the pyrimidine nucleoside phosphorylase PyNP-04 as biocatalyst. The thermodynamic characterization was performed as described previously. ${ }^{[36,37]}$ Reaction equilibria were determined from reactions with $1 \mathrm{mM}$ 2-Se-nucleobase (1 or 2), $5 \mathrm{mM}$ sugar donor (a or b), $5 \mathrm{mM}$ DTT, $50 \mathrm{mM}$ glycine/ $\mathrm{NaOH}$ buffer $\mathrm{pH} 9$ and $50.4 \mu \mathrm{g} \mathrm{mL}^{-1}$ (around $4 \mathrm{U}$ ) PyNP-04 in a total volume of $1 \mathrm{~mL}$. The nitrogen-saturated reaction mixtures were incubated at $60{ }^{\circ} \mathrm{C}$ for the deoxyribosides $\mathbf{1 b}$ and $\mathbf{2 b}$ and $80^{\circ} \mathrm{C}$ for the ribosides $1 \mathbf{a}$ and $2 \mathrm{a}$ until reaction completion (indicated by no further product formation; within $30 \mathrm{~min}$ under these conditions). Samples were diluted to $1 \mathrm{mM}$ sugar donor concentration in $\mathrm{MeOH}$, centrifuged $\left(4^{\circ} \mathrm{C}, 21,500 \mathrm{~g}, 20 \mathrm{~min}\right)$ and analyzed by HPLC.

The equilibrium constants of phosphorolysis of the 2-Sepyrimidine nucleosides were calculated via equilibrium state thermodynamics and numerical solutions. Nucleoside phosphorolysis is a tightly thermodynamically controlled reaction and transglycosylations behave as coupled equilibrium reactions as they comprise a forward and a reverse phosphorolysis. Thus, knowledge of the equilibrium constant of the sugar donor, the concentrations of the starting materials as well as the degree of conversion to the product nucleoside allows calculation of the equilibrium constants of phosphorolysis of the product nucleoside via numerical solutions of the system of coupled equilibrium constraints (see ${ }^{[36,37]}$ ). These numerical solutions can either be obtained via the Python code described in our previous work $^{[44]}$ or, more conveniently, the Excel sheet presented in the externally hosted Supplementary Information of this publication. Herein, we used the previously published equilibrium constants of phosphorolysis of the sugar donors $\mathbf{a}$ and $\mathbf{b}$ for calculation. ${ }^{[38,45]}$ Based on the obtained equilibrium constants, expected conversions for the 2-Senucleosides using a 10-fold sugar donor excess were calculated (please see the externally hosted Supplementary Information for details). ${ }^{[34,44]}$ To verify the theoretical calculations and to monitor the reaction progression, reactions with $5 \mathrm{mM}$ 2-Se-base, $50 \mathrm{mM}$ sugar donor, $5 \mathrm{mM}$ DTT in $50 \mathrm{mM}$ glycine/ $\mathrm{NaOH}$ buffer $\mathrm{pH} 9$ saturated with nitrogen and $24.64 \mu \mathrm{g} \mathrm{mL}^{-1}$ (around $2 \mathrm{U}$ ) PyNP-04 in a total volume of $1 \mathrm{~mL}$ were performed at $60^{\circ} \mathrm{C}$ for the deoxyribosides and $80{ }^{\circ} \mathrm{C}$ for the ribosides. Samples were diluted 50-fold in $\mathrm{MeOH}$, centrifuged $\left(4{ }^{\circ} \mathrm{C}, 21,500 \mathrm{~g}\right.$, $20 \mathrm{~min}$ ) and analyzed by HPLC.

\section{Analytical High-performance liquid chromatography (HPLC)}

Analytical HPLC analyses were carried out with an Agilent 1200 series system equipped with an Agilent DAD detector using a Phenomenex (Aschaffenburg, Germany) reversed phase Kinetex EVO C18 column $(250 \times 4.6 \mathrm{~mm})$. Samples were analyzed at two wavelengths $(\lambda=260 \mathrm{~nm}, 307 \mathrm{~nm})$ at

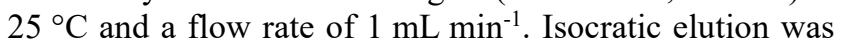
performed using 97\% $20 \mathrm{mM}$ ammonium acetate buffer and $3 \%$ acetonitrile for $7 \mathrm{~min}$ followed by a linear gradient to $60 \% 20 \mathrm{mM}$ ammonium acetate buffer and $40 \%$ acetonitrile over $8 \mathrm{~min}$. Afterwards, the initial conditions were restored and maintained for $4 \mathrm{~min}$.

Conversions were determined by quantifying the 2-Senucleosides 1a-2b and 2-Se-nucleobases $\mathbf{1}$ and $\mathbf{2}$ at $307 \mathrm{~nm}$ using equation (2), whereby $P_{X}$ is the peak area of compound $\mathrm{X}$ and $P_{\text {total }}$ is the sum of all peak areas at $307 \mathrm{~nm}$. Substrates and products were identified based on their retention time and UV absorption spectra by 
comparison to authentic standards. Typical retention times under these conditions were as follows: 1: $3.4 \mathrm{~min}, 2: 6 \mathrm{~min}$, a: $3.6 \mathrm{~min}, \mathbf{b}: 8.6 \mathrm{~min}$, a'": $3 \mathrm{~min}$, b": $4.5 \mathrm{~min}, \mathbf{1 a}: 7 \mathrm{~min}$, 1b: $12 \mathrm{~min}, \mathbf{2 a}: 12 \mathrm{~min}$ and $\mathbf{2 b}$ : $13 \mathrm{~min}$. a' and b' are not UV-active and cannot be detected with a DAD system.

$$
\text { Conversion }(X)[\%]=100 \times \frac{P_{X}}{P_{\text {total }}}
$$

Synthesis of 2-Se pyrimidine nucleosides in semipreparative scale

2-Se nucleosides were synthesized in a reaction volume of $50 \mathrm{~mL}$ consisting of $5 \mathrm{mM} 2-\mathrm{Se}$ base (1 or 2), $50 \mathrm{mM}$ sugar donor (a or b), $5 \mathrm{mM}$ DTT, $50 \mathrm{mM}$ glycine/ $\mathrm{NaOH}$ buffer pH 9 and $24.6 \mu \mathrm{g} \mathrm{mL}^{-1}$ (a: 98.5 U, b: 97.4 U) PyNP-04. The reaction mixture was saturated with nitrogen. Deoxyribosyl derivatives were prepared at $60{ }^{\circ} \mathrm{C}$ and ribosyl derivatives at $80{ }^{\circ} \mathrm{C}$. The reactions were stopped after 3 to $5 \mathrm{~h}$ by a pH shift to 13 through addition of $10 \mathrm{M} \mathrm{NaOH}$ (monitored with a $\mathrm{pH}$-electrode). The $\mathrm{pH}$ was shifted back to 9 using $25 \%$ $\mathrm{HCl}$ and proteins were removed by filtration at room temperature using a vacuum pump and $0.45 \mu \mathrm{m}$ cellulose nitrate filters (Sartorius, Goettingen, Germany). The filtrate was saturated with nitrogen and stored at $4{ }^{\circ} \mathrm{C}$ until purification.

\section{Purification of 2-Se pyrimidine nucleosides by Silica column chromatography}

The first purification step was performed at room temperature via column chromatography $(10 \% \mathrm{MeOH}$ in DCM) using a Sigma-Aldrich silica gel (pore size 60; mesh particle size 220-440; particle size 35-75 $\mu \mathrm{m}$ ). The reaction mixture was adsorbed onto silica gel by addition of $1.8 \mathrm{~g}$ of silica to the aqueous reaction mixture and evaporation of the solution in vacuo. The resulting powder was stored at $-20{ }^{\circ} \mathrm{C}$ until loading on a silica column for purification. Collected fractions were analyzed by TLC $(10 \% \mathrm{MeOH}$ in DCM) using UV detection. Fractions containing the 2-Senucleoside were combined and dried under reduced pressure and stored at $-20{ }^{\circ} \mathrm{C}$ until further purification by semipreparative HPLC.

\section{Purification of 2-Se pyrimidine nucleosides by semi- preparative HPLC}

2-Se-nucleosides were further purified at room temperature using a Knauer HPLC system equipped with a Smartline Detector 2600 and an Azura P2.1 L pump. A reversed phase Kinetex ${ }^{\circledR} 5 \mu \mathrm{m}$ Evo C18 column $(250 \times 21.2 \mathrm{~mm})$ and a flow rate of $21.24 \mathrm{~mL} \mathrm{~min}^{-1}$ were used. Samples were analyzed at $210 \mathrm{~nm}$. Deionized water and acetonitrile were applied as eluents, while the gradient was modified from the analytical method as summarized in Table S2. The product purified by silica chromatography was dissolved in deionized water (Table S2) and filtered either with a $0.45 \mu \mathrm{m}$ PES syringe filter or with a $0.45 \mu \mathrm{m}$ cellulose nitrate filter using a vacuum pump. The collected product fractions were kept on ice to prevent product degradation during the purification process. Collected 2-Se-nucleoside fractions were dried using a Christ Gamma 1-20 freezedryer (Osterode am Harz, Germany).

\section{LC-MS analysis}

For LC-MS analysis, $0.1 \mathrm{mg}$ sample was dissolved in $1 \mathrm{~mL}$ water in a HPLC vial. Samples were analyzed using a HPLC Agilent 1200 series system coupled to an ESI-Orbitrap-MS (Thermofisher LTQ Orbitrap XL). The LC analyses were carried out using a Grace reversed phase GROM-Sil-ODS4 -HE column $(50 \times 2 \mathrm{~mm}, 3 \mu \mathrm{m})$. Samples were analyzed at $20{ }^{\circ} \mathrm{C}$ and at three wavelengths $(\lambda=215 \mathrm{~nm}, 280 \mathrm{~nm}$, $350 \mathrm{~nm})$. A flow rate of $0.3 \mathrm{~mL} \mathrm{~min}^{-1}$ was applied. The gradient was linearly increased from $80 \% 0.1 \% \mathrm{HCOOH}$ in water and $20 \% 0.1 \% \mathrm{HCOOH}$ in $\mathrm{ACN}$ to $100 \% 0.1 \%$ $\mathrm{HCOOH}$ in $\mathrm{ACN}$ in $10 \mathrm{~min}$. The mobile phase composition was held for 3 min at $100 \% 0.1 \% \mathrm{HCOOH}$ in ACN. Finally, the initial conditions were restored and maintained for 5 min. The raw data was analyzed using FreeStyle (Thermo Scientific).

Compound characterization (also see Figures S6-S9)

2-Selenouridine (1a): off-white powder, $R_{f}=0.29$ (DCM/MeOH 9:1); UV/Vis (4.5\% ACN in $20 \mathrm{mM} \mathrm{NH}_{4} \mathrm{Ac}$ $\mathrm{pH}$ 6.8): $\lambda_{\max }=307 \mathrm{~nm}$; HRMS (ESI): $m / z$ calcd for $\mathrm{C}_{9} \mathrm{H}_{12} \mathrm{~N}_{2} \mathrm{O}_{5} \mathrm{Se}+\mathrm{H}^{+}: 308.9984[M+\mathrm{H}]^{+}$; found: 308.9986

2 '-Deoxy-2-Selenouridine (1b): yellow powder, $R_{f}=0.39$ (DCM/MeOH 9:1); UV/Vis (26\% ACN in $20 \mathrm{mM} \mathrm{NH}_{4} \mathrm{Ac}$ pH 6.8): $\lambda_{\max }=307 \mathrm{~nm}$; HRMS (ESI): $\mathrm{m} / \mathrm{z}$ calcd for $\mathrm{C}_{9} \mathrm{H}_{12} \mathrm{~N}_{2} \mathrm{O}_{4} \mathrm{Se}+\mathrm{H}^{+}: 293.0035[M+\mathrm{H}]^{+}$; found: 293.0036

5-Methyl-2-selenouridine (2a): slightly cream-colored powder, $R_{f}=0.38(\mathrm{DCM} / \mathrm{MeOH} 9: 1)$; UV/Vis $(26 \% \mathrm{ACN}$ in $20 \mathrm{mM} \mathrm{NH}_{4} \mathrm{Ac}$ pH 6.8): $\lambda_{\max }=307 \mathrm{~nm}$; HRMS (ESI): $\mathrm{m} / z$ calcd for $\mathrm{C}_{10} \mathrm{H}_{14} \mathrm{~N}_{2} \mathrm{O}_{5} \mathrm{Se}+\mathrm{H}^{+}$: $323.0141[M+\mathrm{H}]^{+}$; found: 323.0144

2-Selenothymidine (2b): off-white powder, $R_{f}=0.43$ (DCM/MeOH 9:1); UV/Vis $\left(30 \% \mathrm{ACN}\right.$ in $20 \mathrm{mM} \mathrm{NH}_{4} \mathrm{Ac}$ pH 6.8): $\lambda_{\max }=307 \mathrm{~nm}$; HRMS (ESI): $m / z$ calcd for $\mathrm{C}_{10} \mathrm{H}_{14} \mathrm{~N}_{2} \mathrm{O}_{4} \mathrm{Se}+\mathrm{H}^{+}$: $307.0192[M+\mathrm{H}]^{+}$; found: 307.0194

\section{Acknowledgements}

We thank the Mass Spectrometry Analytical Center of the Institute of Chemistry of Technische Universität Berlin for analysis of our samples. K.F.H. was funded by the Deutsche Forschungsgemeinschaft (DFG, German Research Foundation) - grant number 392246628.

\section{Conflict of Interest}

A. K. is CEO of the biotech company BioNukleo $\mathrm{GmbH}$. F. K. is a scientist at BioNukleo GmbH and P. N. is a member of the advisory board. These affiliations constitute no conflict of interest with the results presented and discussed in this report.

\section{Author Information \\ Corresponding Author \\ Dr. Anke Kurreck, anke.wagner@tu-berlin.de, orcid.org/0000-0001-6919-725X}

\section{Other Authors}

Katja F. Hellendahl, orcid.org/0000-0002-5408-3679

Felix Kaspar, orcid.org/0000-0001-6391-043X

Dr. Xinrui Zhou, orcid.org/0000-0002-7104-6749

Zhaoyi Yang, orcid.org/0000-0003-3880-1199

Dr. Zhen Huang, orcid.org/0000-0002-8640-3227

Dr. Peter Neubauer, orcid.org/0000-0002-1214-9713 


\section{References}

[1] J. Sheng, Z. Huang, Chem. Biodivers. 2010, 7, 753-785.

[2] L. Lin, J. Sheng, Z. Huang, Chem. Soc. Rev. 2011, 40, 4591-4602.

[3] W. Zhang, J. W. Szostak, Z. Huang, Front. Chem. Sci. Eng. 2016, 10, 196-202.

[4] A. Serganov, S. Keiper, L. Malinina, V. Tereshko, E. Skripkin, C. Hobartner, A. Polonskaia, A. T. Phan, R. Wombacher, R. Micura, et al., Nat. Struct. Mol. Biol. 2005, 12, 218-224.

[5] A. Serganov, Y.-R. Yuan, O. Pikovskaya, A. Polonskaia, L. Malinina, A. T. Phan, C. Hobartner, R. Micura, R. R. Breaker, D. J. Patel, Chem. Biol. 2004, 11, 1729-1741.

[6] M. Egli, P. S. Pallan, R. Pattanayek, C. J. Wilds, P. Lubini, G. Minasov, M. Dobler, C. J. Leumann, A. Eschenmoser, J. Am. Chem. Soc. 2006, 128, 10847-10856.

[7] S. Freisz, K. Lang, R. Micura, P. Dumas, E. Ennifar, Angew. Chemie Int. Ed. 2008, 47, 41104113.

[8] L. Lin, J. Sheng, R. K. Momin, Q. Du, Z. Huang, Nucleosides. Nucleotides Nucleic Acids 2009, 28, 56-66.

[9] A. F. Ross, K. C. Agarwal, S. H. Chu, R. E. J. Parks, Biochem. Pharmacol. 1973, 22, 141-154.

[10] P. K. Sahu, T. Umme, J. Yu, G. Kim, S. Qu, S. D. Naik, L. S. Jeong, Molecules 2017, 22, DOI 10.3390/molecules22071167.

[11] P. K. Sahu, G. Kim, A. Nayak, J. Y. Ahn, M. W. Ha, C. Park, J. Yu, H. Park, L. S. Jeong, Asian J. Org. Chem. 2016, 5, 183-186.

[12] P. K. Sahu, T. Umme, J. Yu, A. Nayak, G. Kim, M. Noh, J.-Y. Lee, D.-D. Kim, L. S. Jeong, J. Med. Chem. 2015, 58, 8734-8738.

[13] I. Di Leo, F. Messina, V. Nascimento, F. G. Nacca, D. Pietrella, E. J. Lenardão, G. P. and L. Sancineto*, Mini. Rev. Org. Chem. 2019, 16, 589-601.

[14] J. Caton-Williams, Z. Huang, Angew. Chem. Int. Ed. Engl. 2008, 47, 1723-1725.

[15] D. S. Wise, L. B. Townsend, J. Heterocycl. Chem. 1972, 9, 1461-1462.

[16] C. Y. Shiue, S. H. Chu, J. Org. Chem. 1975, 40, 2971-2974.

[17] H. Sun, J. Sheng, A. E. A. Hassan, S. Jiang, J. Gan, Z. Huang, Nucleic Acids Res. 2012, 40, 5171-5179.

[18] P. Bartos, A. Maciaszek, A. Rosinska, E. Sochacka, B. Nawrot, Bioorg. Chem. 2014, 56, 49-53.

[19] M. Kogami, D. R. Davis, M. Koketsu, Heterocycles 2016, 92, 64-74.

[20] A. E. A. Hassan, J. Sheng, W. Zhang, Z. Huang, J. Am. Chem. Soc. 2010, 132, 2120-2121.

[21] A. Roy, C. Conlee, A. Fougerolles, Modified Nucleic Acid Molecules and Uses Thereof, 2014, WO 2014/093924 AI.
[22] X. Zhou, W. Yan, C. Zhang, Z. Yang, P.

Neubauer, I. A. Mikhailopulo, Z. Huang, Catal. Commun. 2019, 121, 32-37.

[23] F. Kaspar, M. R. L. Stone, P. Neubauer, A. Kurreck, ChemRxiv 2020, DOI 10.26434/chemrxiv.12753413.v1.

[24] S. Kamel, M. Weiß, H. F. T. Klare, I. A. Mikhailopulo, P. Neubauer, A. Wagner, Mol. Catal. 2018, 458, 52-59.

[25] C. M. Alder, J. D. Hayler, R. K. Henderson, A. M. Redman, L. Shukla, L. E. Shuster, H. F. Sneddon, Green Chem. 2016, 18, 3879-3890.

[26] I. A. Mikhailopulo, A. I. Miroshnikov, Acta Naturae 2010, 2, 36-59.

[27] I. Mikhailopulo, Curr. Org. Chem. 2007, 11, 317335.

[28] N. C. Payne, A. Geissler, A. Button, A. R. Sasuclark, A. L. Schroll, E. L. Ruggles, V. N. Gladyshev, R. J. Hondal, Free Radic. Biol. Med. 2017, 104, 249-261.

[29] B. Hu, Y. Wang, S. Sun, W. Yan, C. Zhang, D. Luo, H. Deng, L. R. Hu, Z. Huang, Angew. Chemie Int. Ed. 2019, 58, 7835-7839.

[30] H. Moroder, C. Kreutz, K. Lang, A. Serganov, R. Micura, J. Am. Chem. Soc. 2006, 128, 9909-9918.

[31] BioNukleo, "Prokaryotic pyrimidine nucleoside phosphorylase 4," can be found under https://www.bionukleo.com/shop/np/y04/, 2020.

[32] H. G. Mautner, J. Am. Chem. Soc. 1956, 78, 5292-5294.

[33] R. T. Giessmann, F. Kaspar, in preparation.

[34] F. Kaspar, K. F. Hellendahl, Zenodo 2020, DOI 10.5281/zenodo.4302012.

[35] F. Kaspar, R. T. Giessmann, S. Westarp, K. F. Hellendahl, N. Krausch, I. Thiele, M. C. Walczak, P. Neubauer, A. Wagner, Chembiochem 2020, DOI 10.1002/cbic.202000204.

[36] H. Yehia, S. Westarp, V. Rohrs, F. Kaspar, R. T. Giessmann, H. F. T. Klare, K. Paulick, P. Neubauer, J. Kurreck, A. Wagner, Molecules 2020, 25, DOI 10.3390/molecules25040934.

[37] F. Kaspar, R. T. Giessmann, K. F. Hellendahl, P. Neubauer, A. Wagner, M. Gimpel, Chembiochem 2019, DOI 10.1002/cbic.201900740.

[38] F. Kaspar, R. T. Giessmann, P. Neubauer, A. Wagner, M. Gimpel, Adv. Synth. Catal. 2020, 362, 867-876.

[39] C. S. Alexeev, M. S. Drenichev, E. O. Dorinova, R. S. Esipov, I. V Kulikova, S. N. Mikhailov, Biochim. Biophys. acta. Proteins proteomics 2020, 1868, 140292.

[40] F. Kaspar, R. T. Giessmann, N. Krausch, P. Neubauer, A. Wagner, M. Gimpel, Methods Protoc. 2019, 2, 60.

[41] J. Reijenga, A. van Hoof, A. van Loon, B. Teunissen, Anal. Chem. Insights 2013, 8, 53-71.

[42] R. T. Giessmann, N. Krausch, Zenodo 2019, DOI 10.5281/ZENODO.3243376.

[43] F. Kaspar, Zenodo 2020, DOI 10.5281/ZENODO.3723806. 
[44] F. Kaspar, R. T. Giessman, Zenodo 2019, DOI 10.5281/ZENODO.3565561.

[45] F. Kaspar, R. T. Giessman, P. Neubauer, A. Wagner, M. Gimpel, Zenodo 2019, DOI 10.5281/ZENODO.3568858. 